\title{
من مناهج علماء شبه القارة الهندية فى ييار. العقيدة الصحيحة: جهود الشيخ أحمد السرهندى نموذجا
}

\section{Ulama of the Indian subcontinent and their approaches to explain the correct belief: The Contribution of Shaikh Ahmad Al-sarhandi as a Case Study}

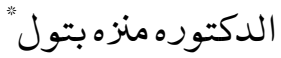

\section{ABSTRACT:}

Mujaddid-e-Alfi Sani Shaikh Ahmad al-Fārūqī al-Sirhindī (1564-1624) was an Indian Islamic scholar, a Hanafi jurist, and a prominent member of the Naqshbandī Sufi order. He has been described as a Mujaddid, meaning "the reviver" for his work in rejuvenating Islam and opposing the newly made religion of Din-i Ilahi and other dissident opinions of Mughal emperor Akbar. Shaikh Ahmad Sirhindi's teaching emphasized the inter-dependence of both the Sufi path and sharia, stating that "what is outside the path shown by the prophet is forbidden. Shaykh Ahmad Sirhindi advanced the notion of wahdat ash-shuhūd (oneness of appearance). According to this doctrine, the experience of unity between God and creation is purely subjective and occurs only in the mind of the Sufi who has reached the state of fana' fi Allah (to forget about everything except Almighty Allah). Sirhindi consi-dered wahdat ash-shuhūd to be superior to wahdat al-wujūd (oneness of being), which he understood to be a preliminary step on the way to the Absolute Truth.

Key words: Shaikh Ahmad al-Fārūqī, wahdat ash-shuhūd, wahdat al-wujūd.

$$
\begin{aligned}
& \text { يهدف هذا البحث إبراز جهود العلماء المسلمين في شبه القارة الهندية في بيات العقيدة الإسلامية ودراسة مناهجهر } \\
& \text { عموما ودراسة جهود الشيخ أحمد السرهندى خصوصا. إعتنى علماء شبه القارة الهندية في نشر العلوم الدينية و خدمتها قديما و }
\end{aligned}
$$

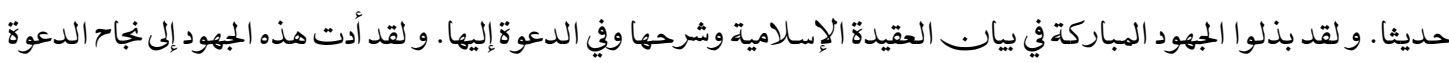

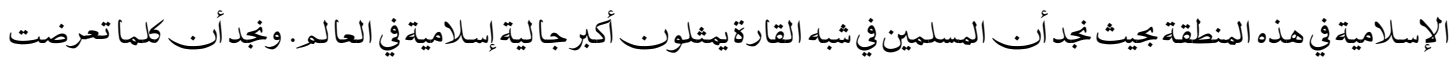

$$
\begin{aligned}
& \text { العقيدة الإسلامية للهجوم الفكري من الداخل أو الخاربج جعل الله سبحانه وتعالى من علماءنا من قام بالدفاء عن العقيدة }
\end{aligned}
$$

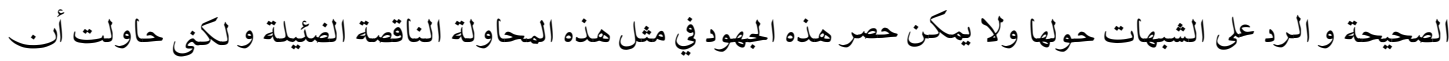

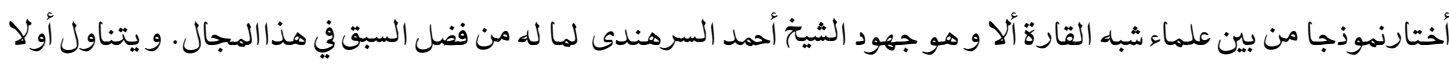

$$
\begin{aligned}
& \text { ترجمة حيات الشيخ, ثانيا نبذة عن عصره وثالثاجهود الشيخف بياب العقيدة الصحيحة من خلال مكتود باته و مؤلفاته و من خلال } \\
& \text { الهصادر التاريخية المعاصرة للشيخ و أخيرا تقييم جهود الشيخ ومدى تأثيره على الفكر الإسلامي في شبه القارة الهندية. } \\
& \text { ترجمةحيات الثيخ: }
\end{aligned}
$$

*Assistant Professor, Faculty of Usool-ud-Din, International Islamic University, Islamabad.

Email: munazza.batool@iiu.edu.pk 
هو الشيخ احمد بن عبد الاحد بن زين الدين الفاروقي النقشبندي السرهندي المنسوب إلى سرهند مدينة تقع بين

دلهى ولاهور و مولده ووفاته فيهاو قد لقب بمجدد الألف الثاني للهجرة. يقول صاحب نزهة الخواطر مترجما له: الإمام العارف بجر الحقائق والإسرار, محي السنة النبوية برهابـ العارفين والمحققين وحجة الاولياء والمتقين آية من آيات الله العظام

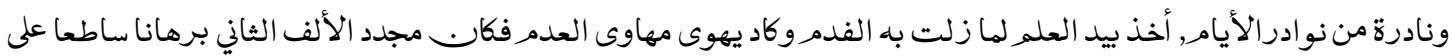

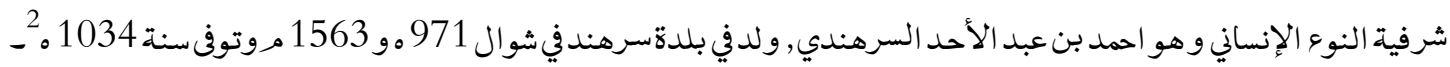
بدأ الشيخ دراساته بجفظ كتاب الله تعالى و قرأ على أبيه أولا واستفاد منه جما منا لعلوم ثمر ارتحل إلى سيالكوت وتتلمذ على يد الشيخ المحقق كمال الدين الكشميري بعض المقولات وأخذ الحديث من الشيخ يعقوب المحدث الكشميري وكابــ أكابر المحدثين بالحرمين الشرفين واسند الحديث عنهم 3

نبذة8ن عصره:

اتفق العلماء المسلمين والمؤرخوبـ على أبـــ الإماه السرهندي قام بالدور الرائع في الدفاء عن الدين ونصرته وصنع عهدا جديدا بما قام بالإصلاح واشتهر بلقب المجدد وظل ينوب هذا للقب عن إسمه فماهذا التجديد والإصلاج؟ قد عاصر الشيخ عصر الفتن والإلماد كما عبر عن ذلك في إحدى رسائله " لقد أصبح الإسلام أجنبيا وعاجزالما تمكن الكفار من السلطة في زماننا و يسخر من الإسلام والمسلمين. تمارس وصايا الكفر علنا في حين يضطر المسلموب. إلى عدم القيامر بأوامر الدين بل

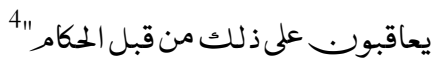
ولا يمكن الإعتر اف بجهودالشيخ فى بيالــ العقيدة الإسلامية الصحيحة إلا إذ نتعرض لذلك الإضطراب الفكري و الفوضى العقدية التي ظهرت وانتشرت في الهند والبلدابــ المجاورةفي العصر الذي عاش فيه الشيخ احمد السرهندى. و لقد أدت العوامل الكثيرة لتعرض هذه المنطقة لأنواع من الإنحرافات العقدية من أهمها:

$$
\begin{aligned}
& \text { أ : بعد الهندعنمركز الإسلامر الديني والثفافي } \\
& \text { ب: عدم الإعتناء بنشر العلوم الشرعية على يد الحكام } \\
& \text { ج: بقاء أقلية المسلمين مغمورة تي اكثرية غيرإسلامية }
\end{aligned}
$$

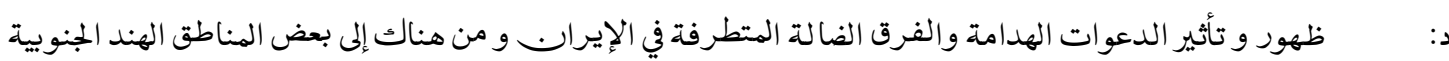
وفي الكشميروكار فـ في مقدمة هذه الفرق التشيع المتطرف و إدعاءات النبوة بل في بعض الأحيالـ إدعاءات الألوهية و فكرة ألفية سوف نذكر بعض هذه الحركات على سبيل المثال لاعلى سبيل الحصر: النقطوية ظهرت هذه الحركة في أستر آباد في الإيرابـ على يد محمود البسيخواني في اوائل القربـ التاسع و ظلت تنموحتى بلغ أتباعها الآلاف وأثرت تأثيرا كبيرا في الإيراس ـو وصلت أيضا في الهندو كانت عقائدهم عبارة عن الإلحاد والزندقة و الإباحة إذ اعتقدوا بقدم العالمـ وأنكروا الحشر والنشور بمفهومها الإسلامي وقالوا بالتناسخ واعتقدوا أبــ القرآـــــن من 
كلامر النبي و أبــ الأحكام الشرعية هي آراء الرجال. فكانوا يستهزؤُ. بالصلاة والحجه و الأضحية و الصيامـو أحكام الطهارة والغسل و أنكروا حرمة النساء المحرمات. وكار. أساس عقيدة بسيخواتـ أر. الدين الإسلامي أصبح منسوخا و أب. الإسلامرقدقضى عمره بمرور ألف سنة و أُ. المدة ما بين نشأة الأرض وظهور البسيخواني ثمانية ألف سنة كانت النبوة محصورة في العرب وأبـ بعد ظهوره انتهت السيادة العريية فلا يبعث نبي إلا في الشعوب العجمية. وحينها قام شاه عباس الصفوي بالتنكيل و التقتيل و التشريد لأتباء هذه الفرقة نظرا لضررهم فر كثير منهم إلى الهند. و كا. لهذه الفكرة الألفية أثر كبيرفى الهندو الذي تمهد لمزيد من الحركات الضالة المنحرفة.

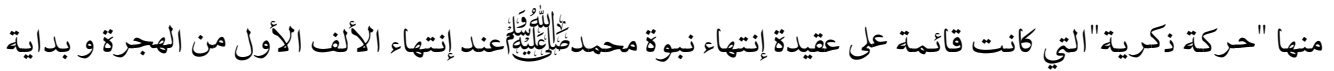
نبوة جديدة لبداية الألف الثاني وقد ظهرت هذه الحركة على يد ملامحمد أتكى والذي إدعى النبوة وأنه من أفضل الأنبياء وخاتم النبيين. و كتب هذه الفرقة تحتوى على العبارات الصريحة التي تدل على عفائدهم المتطرفة والتي عبارة عن الإفتراء والباطل على الله ورسوله و ابتدعوا كلمة جديدة و بدأوا يكجوبـ حهج خاص بهم في جبل مراد بدل حهج بيت الله و كانت هذه الحركة سائدة في بعض مناطق بلوجستالــ ومازالت أقلية من هذه الطائفة موجودة في أنحاء هذ الجبل الذي جعلوه قبلة لهه في بلوجستار. و ظهرت أيضا الفرقة الروشنائية التي أسسها بايزيد والذي كابـ يسمي نفسه بير روشن و كانـ قد إدعى النبوة وكار. يدعى أبـ جبريل ينزل عليه و كار. يعتقد بوحدة الوجود وتناسخ الأرواح وأنكر إستقبال القبلة فى الصلاة والطهارة وكات. الهندوس أيضا من مريديه وسمح لهم أب. يعبدوا بطريقتهم. وخاصة ما قام به الملك الأكبر نفسه بإنشاءدين جديد, وبدأفى سنة 1575 بإنشاء مركزفى فتحبور سكرى والذى سماه عبادت خانه أي دار العبادة والذي كارِ فى رأيه مركزا للحوار والتقريب بين الآراء المختلفة و توحيد الإسلام على

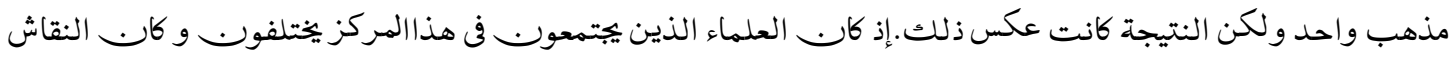
يؤدى إلى إثارة مزيد من الإختلاف وكارـــفى هذالجُوء من الإختلاف أبـــ أمكن الإمبراطور بتوقيء من العلماء الذين كانوا يجتمعونـ في هذا لمركز أبـ يصدر الإعلان. بكونه "الإمامر العادل" الذي يجمه بين السلطة الزمنية و السلطة الروحية الدينية و هكذا تمهد الملك لإنشاء دينه الجديد الذى كار. بزعمه سوف يجمه بين الأديال. ــ والأفكار ليقل الخلاف بين رعاياه. 8 وسمى الهلك أكبر هذا الدين الجديد "دين إلهى" وفرض على أتباعه أُــ يؤمنوا بأُ. أكبر هوخليفة الله على الأرضو

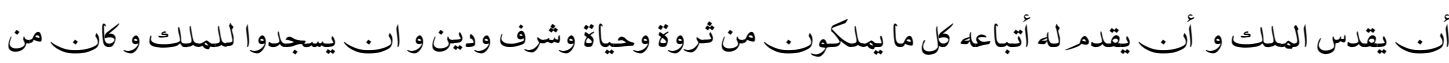
طقوس هذا لدين الجديد المزعوم تقديس الشمس والنار ومنع من أكل لحم البقرةوما إلى ذلك منخرافات كثيرة. وكما هو يظهر

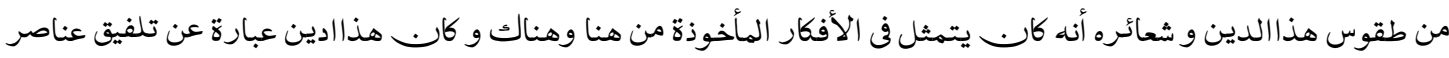
مختلفة بل متناقضة وكار. من سؤء حظ بعض الأمراء والذين كانوا من حوله اهم اعتنقوه.و لم يبتى الأمر قاصراعلى معتنقى هذا الإلحاد فقط بل بدأ الملك بالإدعات الباطلة فبعد أنه كار. يرى نفسه خليفة الله بدأ يدعى الألوهية. وقد جمع حوله نفر من 
الدهريين والملاحدة والحوليين من كل مكات يساعدونه في إدعاته الباطلة. و لمـ يقفوا بهذه الإدعات فقط بل بدأوا يسخروبـ. من شعائر الإسلام و المسلمين و المؤرخين المعاصرين أوردوا كثيرا من التفاصيل فى بياس. هذالإلحلاد. ومن الأمور المسجلة لهذه الحركة الأكبرية التي تدل على الإخراف والتحول على يد أبو الفضل والذى كاتــ وزيرا للملك و كا.ـ له دور كبير في تكوين وتطوير هذا الإلحاد الأكبري : عبادة النار , عبادة الشمس, السجود للملك, التقويم الإلهي الجديدو الإهتمام بالأعيادو المهرجانات غير الإسلامية, إلغاء الزكوةة, إنكار المعجزات والإسراء والمعراجا و استنكار الختابــ, المنع من الصلاةوالإستهزاء بأركا. الإسلامدوفرائضه. بالإضافة إلى هذه الحركات الضالة نجد أبــ التصوف في الهند كار. قد أصبح خليطا من الشريعة و الفلسفة والسنة واليوكا.وظهرت بعض الطرق الصوفية التي كانت تجمع بين طرق اليوكاوالأذكار الإسلامية وبعضهاكانت أقرب إلى المرتاضين اليوكيين مماكانت من الإسلام وأمثلة ذلك كثيرة منها الصوفية الغيرالمتشرعة مثل الجلالية والمدارية والملنكية.ويمكن الإطلاء على مدى تأثير الفلسفات و الهمارسات الهندية من خلال بعض الكتب الصوفية التي ظهرت في ذلك العصرفمثلاكتاب "جواهر خمسة" و "بحر الحيان" لهحمد غوث كوالياري تدل على مزب الأفكار الهندية بالتصوف الإسلامي. وكاتـ الشيخ قد أدرك هذه الأخطاء الفكريتة و العقدية وعبر عن ذلك قائلا: لقد كثر البدو و المحدثات حتى ليخيل للناظر أربـ بهرا من الظلمات تتلاطمه أمواجه.

\section{جهود الشيخخف ييابـ العقيدة الصحيحة:}

و اهتهـ الشيخ بييالـــ العقيدة السليمة خاصة في الأمور التي مازالت موضء خلاف و نقاش بين الفرق المختلفة من

الصوفية والمتكلمين منخلال رسائله منها:

رد الروافض، المبداوالمعاد، رسائلة تقليلية،مكشفات غيبية،رسالة في إثبات النبوة،آداب المريدين،شرح رباعيات أستاذه خواجه باقى بالله، واشهرآثاره الفكرية مجموعة رسائله المعروفة بإسهـ "مكتوبات" التي أرسلها إلى تلاميذه و مريديه و إلى بعض الشخصيات من العلماءو الأمراء والصوفية. و عدد هذه الرسائل 536 وفي ما يلي نبذة عن أهمر ما قدمه الشيخ في بيالـ العقيدة السليمة:

أ :إصلاح فكرة التوحيدو تنقيتها منشوائب الحلولو الإتحاد: لعل من اهم ما قدمه ألشيخ في مجال العقيدة هو إصلاح فكرة التوحيدو تنقيتها من شوائب الحلول و الإتحادومن الجدير بالذكر أُ. الفكر الصوفي في شبه القارة قدظل يتأرجح بين فكرة الحلول و وحدةالوجود على مر القروبـ قبل الشيخ. بالإضافة إلى ذلك شاعت الاستعارات الهندوسية والهمارسات اليوجية مثل تمارين التنفس "براناياما" وطرق العبادة "أسانا"كانت قد أصبحت أرضية مشتركة في التصوف الإسلامي واليوجا الهندوسية آنذلك.والذي أدى إلى الخلط بين مفهوم التوحيد الإسلامي الخالص لصين فكرة الإتحاد والحلول. ومعأس. الشيخ اتصل منذشبابه بكثير من الطرق الصوفية وخاصة الطريقة النقشبندية فقد قام بإصلاح التصوف ولاسيما النزعات و الأفكار الصوفية القائلة بوحدة الوجود. وذلك لأبــ الكثير من الصوفية فى عصره تأثروا 
بالأفكار الهندوسية وأخذوا الكثير من عقائدهم وممارساتهم وشاعت بينهم الأفكار الخاطئة مثل وحدة الوجود والحلول والإتحاد فركز الشيخ على تفنيد هذه الآ راء والرد عليهاو خاصة ناقش آراء محي الدين بن العربي في وحدة الوجود و رسائل الشيخ ومكتوباته مليئة بأدلته التى تقاجم, فكرة وحدة الوجود وقد أمكن للشيخ أبــيهارب تلك الأفكار الصوفية من خلال تجاربه الذاتية إذنادى الشيخ بفكرة وحدة الشهود والتي أمكن الشيخ من خلاله أر. ينقي الفكر الصوفي من كثير من الأخطاء العقدية في الإعتقاد عن الشه سبحانه وتعالى -

و قد بين من خلال تجاربه الروحية أبـ التوحيد الذي يظهر في أثناء الطريق الصوفي إنما يكوبـ عبارة عن تجربة علم. اليقين و أنه هناك فرق بين العله اليقين وعين اليقين و قسه هذه التجربة إلى قسمين: توحيد وجودي وتوحيد شهودي و أبـ التوحيد الوجودي هوأُــ يعله السالك ويعتقد ابــ الموجود واحدا و يعتقد أبــ غيره معدوما أما التوحيد الشهودي هو مشاهدة الواحد يعني لا يكوبــ مشهود السالك غير واحد أو انه لا يشهد أحداسواهت و يبرهن على هذه التفرقة من خلال

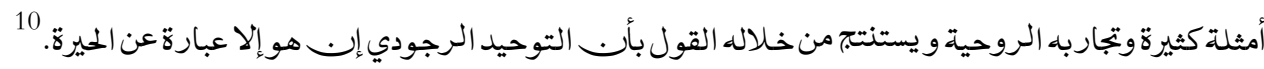

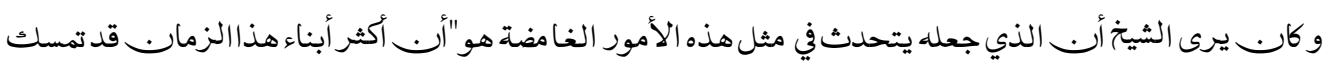
بذيل التوحيد الوجودي بعضهم با لتقليدو بعضهم بمجرد العلمـ و بعضهم بالعلم الممزوبج بالذوق و لو في الجملة و بعضهر بالإلحاد

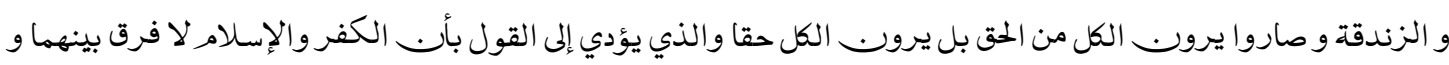
استدل الشيخ على هذا القول من خلال تجربته الذاتية إذ يبين في إحدر رسائله بأنه كابـ قد ترب على نفس الفكة القائلة بوحدة الوجود وأنه كاــــ يعتقد بذلك إلى أبـــأدرك خطورة هذا القول و أنه كابـــلديه مثل هذه الأفكارو قد عبر عن ذلك في بعض رسائله التي أرسلها إلى شيخه في بعض الابيات التي هو يسميها كلمات السكر: أي دريغا كإين شريعت ملت اعماءيست ملة ما كافرى و ملة ترساءيست

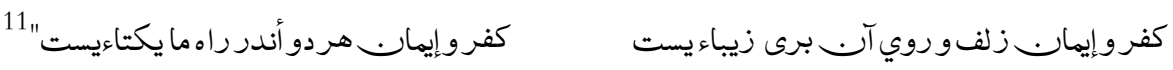
و بعد ابـ كابـ يعتقد بهذا القول هداه الله سبحانه و تعالى وعرف من خلال ما يسميه المعرفة اللدنية أربـ نسبة الوحدة للصانع مع العالم_ليست ثابتة فيقول: "هو تعالى ليس بمتحد بشئ من الاشياء هو هو تعالى وتقدس والعالمـ عالم, و هو تعالى منزه عن الكيف و الكيفيات و العالم متسه بميسم الكيف..... ولايمكن أر. يقال ابـ المنزه عن الكيف عين المكيف

بالكيف و أس الو اجب عين الممكن ولا يكوبـ القديمـعين الحادث و ممتنع العدم عين جائز العدم أصلا."

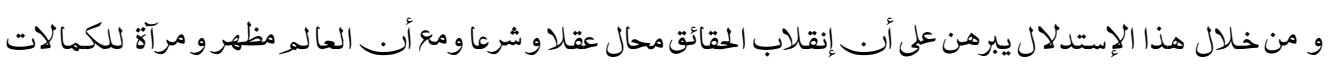
الأسماء و الصفات و لكن المظهر ليس عين الظاهر و الظل ليس نفس الأصل بالإضافة إلى إصلاح الفكر الصوفي قام الشيخ أحمد بنقد العقائدو المهارسات التلفيقية السائدة آنذاك وأشار إلى أنه من الضروري إتاحة مجال كاف للإصلاح لألـــ الأفكار الخاطئة قد أصبحت منتشرة في عامة الناس وخاصتهم. واتجه الشيخ بإصلاح الأفكار التلفيقية فيما يتعلق بفكرة الألوهية بين المسلمين والهندوس و اعترض على الهفكرين الهندوس القائلين بأُ. رامـ و رحيم. فهو لا ينتقد فقط النزعات التوفيقية الشائعة بين 
المسلمين، بل ينتقد أيضا التفسيرات التوا فقية. وكانت مواقفه مؤثرة جدا في فى بيالـ العقيدة الصحيحة وإحياء الإسلام في شبه القارة الهندية. واختار الشيخ منهجج خاصا في بيابـ العقيدة السليمة فبدأ بكتابة الرسائل إلى العلماءو الأمراءو الصوفية و ذلك بمقتضى عصره ونظرا لظروفه الخاصة به. و من خصائص منهج الشيخ في عرض العقيدة الاسلامية على الهندوس بأسلوب الحوار فمثلا الرسالة التي أرسلها إلى واحد هندوسي تدل على فهمه للعقائد الهندوسية و مناقشتها بأسلوب علمي خاص بالشيخ والذي قد لانجد نظيره عند علماء عصره في بيابـ العقيدة الصحيحة وعرضه على الكفار و هاهنا أورد جزء هذه الرسالة القيمة: "ابـ ربناوربكمر رب العالمين من السموت و الأرضين و العلويين والسفليين واحد ليس كمثله شئ منزه عن الشبه والمثلل مبرأ عن

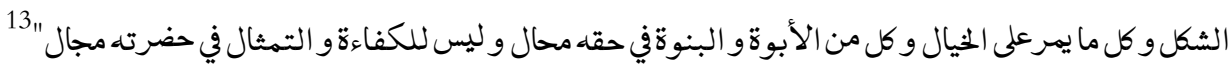

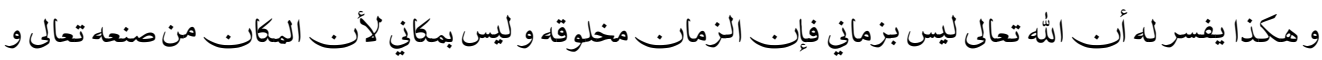
بعد ابـ يشرح العقيدة الاسلامية في الإله يبين الأخطاء الموجودة لدى الهنود و يقول:"ورامـوكرشن و أمثالهما من آلهة الهنود

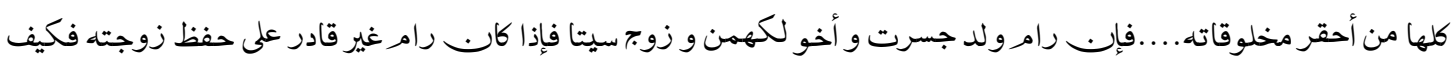
يستطيء أر ــ يساعد الغير".

\section{ب:عناية الشيخ بائبات النبوة والرسالة :}

ولعل من أهم ما قدمه الشيخ بعد إصلاح العقيدة تجاه الخالق هوبيابـ عقيدة الرسالة و اهمية الغعتقاد بالنبي الخاتم عليه أفضل الصلوات والتحيات فقام بترسيخ جذور العقيدة بخلود الرسالة المحمدية في الوقت الذي ظهرت فيه الحركات مثل النقوية والذكرية التي كانت تنادي بأبــ عهد النبوة المحمدية قد انقضى و أنه بمرور ألف سنة انقرضت فترة الرسالة المحمدية. وكانت هذه الفكرة قد أثرت على أكبر الذي جآء بدينه الجديد للألف الجديدة. و من خصائص منهج الشيخ الإهتمام بإصلاح شأُ. الحكومة و رجالها إذ أدرك الشيخ أر. الأمراء والملوك قدوة إذا صلحواصلحت الرعية و إذا فسدوا فسد المجتمع 14 الذى يقوموبـ على شؤنه وكا.ـ بالفعل العصر الذى عاش الشيخ هوعصر الإلحاد والفتن. فنجد أبــ الوزير أبو الفضل وأصحابه من الفلاسفة كانوايروبـ بعد الضرورة إلى النبي و كابــ الشيخ حينما قابل أبو الفضل و أخوه فيضى و تحدث معه في بعض النكات في التفسير "سواطع الألهام" "15 وجد أبو الفضل لا يرى بأبــ النبوة ضرورية و أبــ هذالأمر شائع بين كثيرمن أصحابه اخذ يناقشه فى هذاالامر بالشدة ولذلك نجد أنه عنى عناية كبيرة بعقيدة

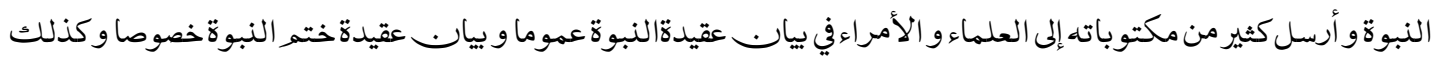
ألف كتابا في إثبات النبوة.

و اتجه الإمام بنقد الفلاسفة والإشراقيين الذين كانوا يدعوبـ المعارف و الكمالات و بين أنه لا طريق إلى هذه الحقائق و المعارف إلاعن طريق أنبياء الله وكار. نقده لهم نقدا علميا موضوعيا وبين أبــ المصدر الأساسي للعله القطعي ليست التأملات العقلية و لا النور الباطني والمشاهدات والكشوفات بل أنبياء الله ووحيه المنزل فيقولفف إحدى رسائله: 
"إذا كانـ العقل يكفي للمعرفة الإلهية لما كالـ فلاسفة اليونابـ الذين جعلوا العقل إمامهـ و قائدهم حيارى تائهين في

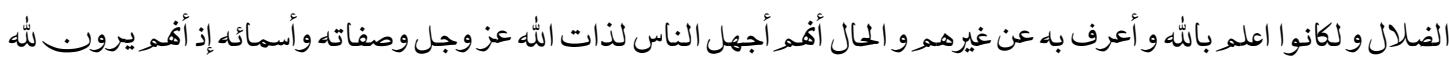
تعالى وجودا يتسمر بالتعطل و البطالة و لايعتقدوب. أنه خلق شيئا سوى واحدهو العقل الفعال وقد كابــ صدوره من الله تعالى |ضطرار لاعن قدرة اخو اختيار"

ثم يبرهن على ضعف هذه المقولة الفلسفية و ايضا يتسائل انه كيف ييجوز تلقيبهـهـ بالحكماء و الإنقياد بهـه إذ عجزهوْلاء بالإعتراف بالإله القادر المطلق وبالتالي يهدم دليل المنحرفين من الدين في عصره بإستنادهم بالفلاسفة. وأثبت على منكري

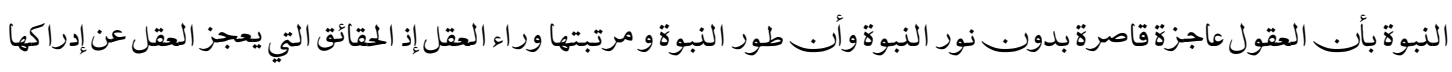

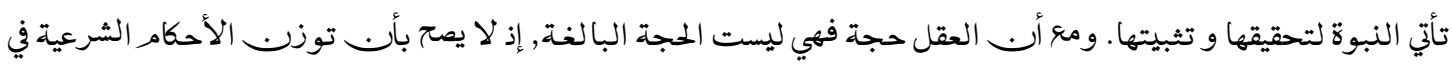
ميزاب العقل و إلـ محاولة التطبيق بين العقلوبين الأحكام الشرعية و الإلتزامربه دائما حكم بكفاية العقل و إنكار للنبوة. د:نقد الفلاسفة والعقلانيين: ولما عاش الشيخ العصر الذي تسود فيه العقلانية و كانت تصريحات الفلسفة اليونانية أصبحت تعتبر من القطعيات البديهيات توجه الشيخ بأسلوب علمي إلى نقدالعقل الخالص و أحكامه و يرى أنه مهما وصل الإنسابــ من صفاء النفس وإشراق الروح فإِ. الأحكام العقلية تتأثر دائما بصلة هذا العقل بالجسم المادي وبالتالي لايمكن أصلا أب. تكوبـ أحكامه و نتائجه متحررة من قيود الوهم والخيال و تبتى موضع شك ولايتحقق فيها الصدق. كما أنه تناول موضوع الكشف الخالص و الإلهام الخالص و تبين

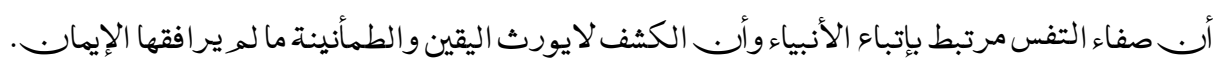
ه : الإمامة وموقف أمل السنة لدى الشيخ: و كاتــ يهتم الشيخ ببيالـــ موقف أهل السنة و الجماعة والعقيدة الصحيحة فيما يتعلق بنظرية الإمامة و بتفضيل الخلفاء الر اشدين و محبة الصحابة رضوابـ الله تعالى عليهم أجمعين و كابــ ذلك موضوعا لكثير من مكتوباته و ذلك نظرا لما شاء الخلاف فيما يتعلق بفكرة الإمامة في عصره وخاصة لما أدى إلى ذلك النفوذ الشيعي من الخلط فى مفهوم الإمامة, فأكد الشيخ بأنه من علامات أهل السنة و الجماعة تفضيل الشيخين و محبة الختنين إذ ثبت ذلك بإجماء الصحابة والتابعين فيقول فى إحدى مكتوباته: "وتفضيل الشيخين ثابت بإجماء الصحابة و التابعين. كما نقل أكابر الأمة منهــ الإمام الشافعي رحمه الله, وقال الشيخ أبوالحسن الأشعري,إٕن تفضيل ابي بكروعمررضي الله عنهماعلى سائرالأمة امرقطعي,وقدثبت عن علي كرم الله وجهه بالتواتر

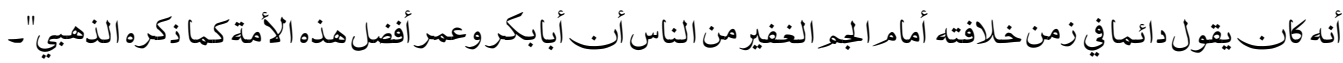
وهكذا يورد أقو الاكثيرة عن الصحابة والتابعين و يثبت أستـ القول بتفضيل الشيخين على سائر الصحابة قد بلغ من كثرة

الرواة الثقات حد التواترو إنكاره إن. هو إلا الجهل والتعصب كما أنه يؤكد على أت. محبة علي و أهل البيت أيضا جزء من التسنن. 


\section{تقييرجهود الثيخو مكانته في مجال العقيدة وإصلاحها:}

و أخيرا من الضروري جدا أر.ـ ننظر إلى الشيخ أحمد السرهندي و جهوده بنظرة التقدير و الإعتبار وذلك لما قام بدوره الإصلاحي في اللوقت الذي عم فيه الإنحرف العقدى على مستوى رجال الحكومة, فقام الشيخ بإعلاء كلمة الحقى أمام الملك

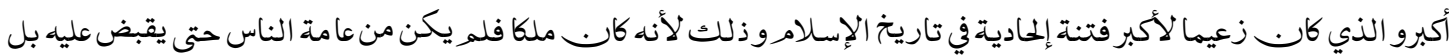
نفسه كا. ــ صاحب الأمر و على العكس فإنه تمكن بإقناء الآخرين للدخول في هرطقته الأكبرية التي كانت قائمة على رفض جميع العقائد الإسلامية من التوحيد والنبوة والسمعيات و تدعو إلى كثير من العقائد والمهارسات مثل عبادة الشمس والناروما إلى ذلك من أمور تنافى العقيدة الإسلامية والشريعة. فقام الشيخ بنقد هذه الإدعات الباطلة وكابــــالأسلوب الذي إختاره الشيخ لبيالـ العقيدة الإسلامية يدل على أنه خطط لهذا العمل الإصلاحي فبدأ بكتابة الرسائل إلى أصحاب السلطة والأمراء و العلماء في شأُ. بيابــ العقيدة والأخذ بالكتاب والسنة. وإنه لما لاحظ الإهتمامر بالعلوم الفلسفية والعقلية قام ببيا. عجز العقل الخالص و نقده. ومعأسـ الشيخ لمر يترك مؤلفات مستقلة في جميء مباحث العقيدة فإِـــ المتعمق في رسائله سوف يجد أســ جل إهتما مله كانت القضايا العقدية التي كانت محور اللنقاش آنذاك بين الطوائف الصوفية أو الحركات الباطلة. فهذه الرسائل التي يبلغ عددها إلى خمسمائة وثلاثة و ستوبل بعضها موجهة إلى أصحاب السلطة والأخرى إلى العلماء و بعضها إلى أصحاب الآراء الخاطئة و يقوم الشيخ فيها ببياب. موقف أهل السنة و الجماعة وأئمة السلف في أمور العقيدةويجمه الشيخ بين أسلوب علمي وصوفي في شرح هذه الأمور العقدية. واستمر الإمام طوال حياته في جهوده الإصلاحية من خلال التوجيه والإرشاد إلى ما كار. الصحيح في الإعتقاد إلى أب. تولى إبن الملك أكبرجهانكير أمور الدولة بعدوفات أبيه. و الذي أدى إلى إعتقاله ايضا و لكن ظل الشيخ يقوم بعمله الإصلاحى و هوكا. في السجن وكار. قد مكث سنتين أو أكثرفي السجن يواصل دعوته إلى التمسك بالعقيدة السليمة تجاه الله و رسوله وأكد على اهمية إتباء السنة والشريعة,إلى أبــ أدرك الملك عن مكانته الدينية وسمعته الشريفة وحكم. بأ. ــ يطلق سراحه لما بلغتـ إليه من احوال الشيخ و هو في السجن, إذ صار قطاء الطريق يصلوبـ و يزكوبـ نتيجة لتوجيه الشيخ وإرشادهم إلى الحق. الأمر الذي جعله يندم على قبض اشيخ و كار. جهانكير قد أثر فيه موقف الإمام الحاسمفى رفض السجدة التعظيمية للملك من

و اخيرا من الواجب علي كطالبة علم أبـــ اشير إلى النقد الذي وجه إلى الشيخ أيضا, فقد أخذ علي الشيخ في بعض مقولاته أثناء بيانه لبعض الأحوال والكشوف التى كانت عبارة عن تجربته الروحية في تكييف ما يسميه هوب"عين اليقين" وكذلك اعترض عليه أنه تحدث عن مرتبته و مقا مه مثل مرتبة أصحاب النبي رضوابـ الله عليهر أجمعين وفيما تحدث في إحدى رسائله عن الحقيقة المحمدية وحقيقة الكعبة وما إلى ذلك من عبار ات و تعبيرات, فيمكن الجواب عنهاو عن مثلهابوجوه:

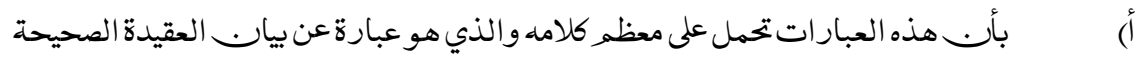


ب) أنه لا يقصد بهذه العبارات عين المراد بها كما ذكر هو نفسه بأنه لا يذكرهذه الأحوال الخلاصة إلاللمنفعة وهي إصلاج

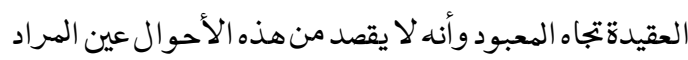

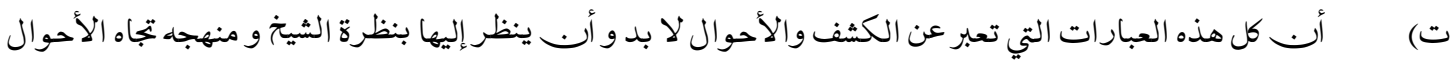

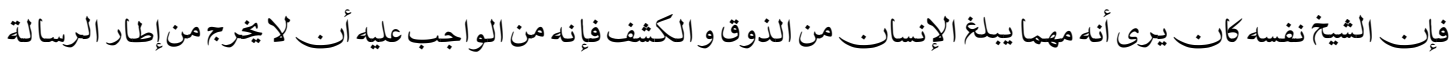

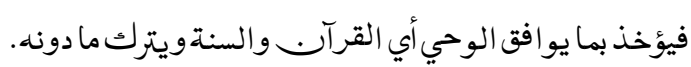

\section{الهوامش}

$$
\begin{aligned}
& \text { 1كابـ فاروقي الأصل وقد أورد نسبه بدرالدين السرهندى في كتابه "حضرات القدس" } \\
& \text { 2أبجد العلوم للصديق بن أحمد القنوجي دار الكتب العلمية, لبناب. } \\
& \text { 3ثف الظنوب لحابى خليفة, ص } 225
\end{aligned}
$$

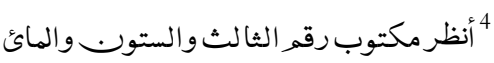

$$
\begin{aligned}
& \text { 5أنظر ما ذكره صاحب الكتاب"دبستاب الهذاهب" فيما يتعلق بأفكار هذه الطائفة ص300 }
\end{aligned}
$$

6 ومن بين الكتب المتداولة لهذه الفئة:شيخ عزيز لارى,سفرنا مهءمهدى,شاه محمدقندى,سيرجهانى, محمدإسحاق درزئى, ذكر إلهى, وتقوم

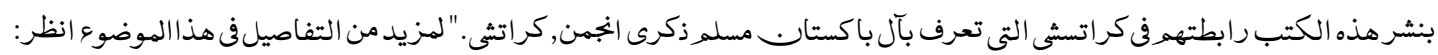

${ }^{7}$ Tariq Ahmed. Religio- Political Ferment in the North West Frontier During the Mughal Period, The Raushniyah Movement (Delhi: Idara e Adabiat,200)

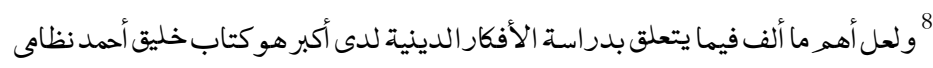

Nizami, Khaliq Ahmed. Akbar and Religion (Delhi: Idara e Adabiyat, / Makhan Lal Roy Choudhury. The Din e Ilahi or the Religion of Akbar (New Delhi: Munshi Manohar Lal Press1952)

$$
\begin{aligned}
& 9 \text { عبد القادر بدايونى, منتخب التواريخ, جزء,2ص225 }
\end{aligned}
$$

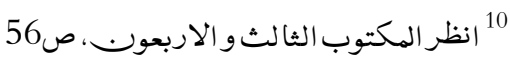

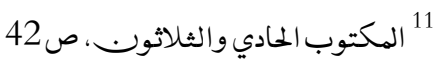

$$
\begin{aligned}
& 12 \text { نفس المكتوب } \\
& \text { 13 الهكتوب السابع و الستوبــــو الهائة إلى هردة رام } \\
& \text { 14 الهكتوب الرابع والأربعوبـ إلى سيد فريد الهيد }
\end{aligned}
$$

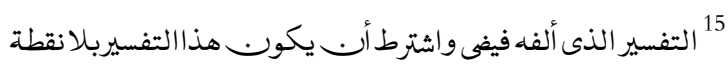

$$
\begin{aligned}
& \text { 16 المكتوب رقم } 23
\end{aligned}
$$

\section{(c) (†)}

This work is licensed under a Creative Commons Attribution 4.0 International License. 